\title{
Virtual Reality Smartphone-Based Intervention for Smoking Cessation: Pilot Randomized Controlled Trial on Initial Clinical Efficacy and Adherence
}

Emilio Goldenhersch ${ }^{1}$, BA; Johannes Thrul ${ }^{2}$, PhD; Joaquín Ungaretti ${ }^{3,4}, \mathrm{PhD}$; Nicolas Rosencovich ${ }^{5}$, BSc; Cristian Waitman $^{6}, \mathrm{BA}$; Marcelo Rodriguez Ceberio ${ }^{1,7,8}, \mathrm{PhD}$

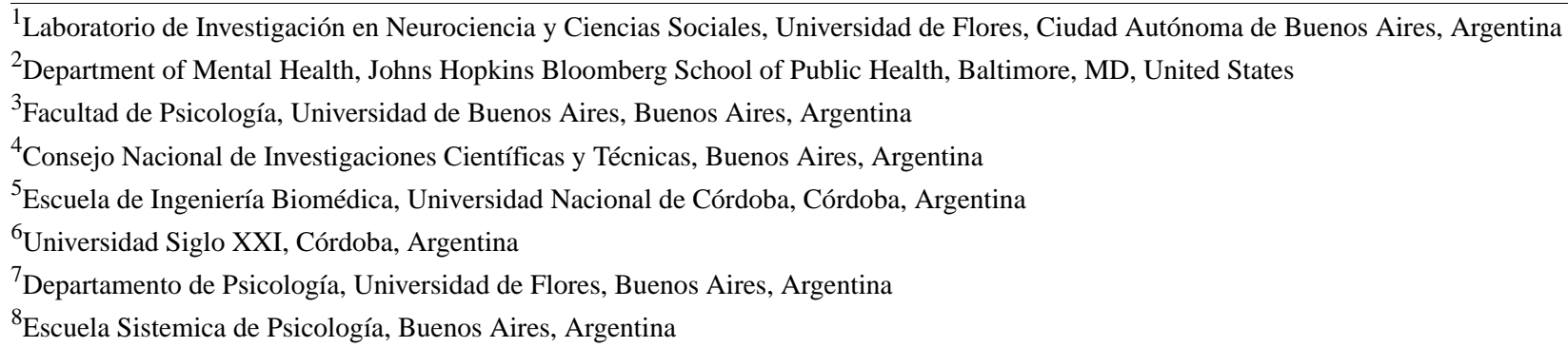

\section{Corresponding Author:}

Emilio Goldenhersch, BA

Laboratorio de Investigación en Neurociencia y Ciencias Sociales

Universidad de Flores

Avenida Rivadavia 5741

Ciudad Autónoma de Buenos Aires, CP 1414

Argentina

Phone: 14808860102

Email: emiliogolden@gmail.com

\section{Abstract}

Background: Obstacles to current tobacco cessation programs include limited access and adherence to effective interventions. Digital interventions offer a great opportunity to overcome these difficulties, yet virtual reality has not been used as a remote and self-administered tool to help increase adherence and effectiveness of digital interventions for tobacco cessation.

Objective: This study aimed to evaluate participant adherence and smoking cessation outcomes in a pilot randomized controlled trial of the digital intervention Mindcotine (MindCotine Inc) using a self-administered treatment of virtual reality combined with mindfulness.

Methods: A sample of 120 participants was recruited in the city of Buenos Aires, Argentina (mean age 43.20 years, SD 9.50; 57/120, 47.5\% female). Participants were randomly assigned to a treatment group (TG), which received a self-assisted 21-day program based on virtual reality mindful exposure therapy (VR-MET) sessions, daily surveys, and online peer-to-peer support moderated by psychologists, or a control group (CG), which received the online version of the smoking cessation manual from the Argentine Ministry of Health. Follow-up assessments were conducted by online surveys at postintervention and 90-day follow-up. The primary outcome was self-reported abstinence at postintervention, with missing data assumed as still smoking. Secondary outcomes included sustained abstinence at 90-day follow-up, adherence to the program, and readiness to quit.

Results: Follow-up rates at day 1 were 93\% (56/60) for the TG and 100\% (60/60) for the CG. At postintervention, the TG reported $23 \%(14 / 60)$ abstinence on that day compared with 5\% (3/60) in the CG. This difference was statistically significant $\left(\chi_{1}^{2}=8.3 ; P=.004\right)$. The TG reported sustained abstinence of 33\% (20/60) at 90 days. Since only 20\% (12/60) of participants in the CG completed the 90-day follow-up, we did not conduct a statistical comparison between groups at this follow-up time point. Among participants still smoking at postintervention, the TG was significantly more ready to quit compared to the CG (TG: mean 7.71, SD 0.13; CG: mean 7.16, SD 0.13; $P=.005)$. A total of $41 \%(23 / 56)$ of participants completed the treatment in the time frame recommended by the program. 
Conclusions: Results provide initial support for participant adherence to and efficacy of Mindcotine and warrant testing the intervention in a fully powered randomized trial. However, feasibility of trial follow-up assessment procedures for control group participants needs to be improved. Further research is needed on the impact of VR-MET on long-term outcomes.

Trial Registration: ISRCTN Registry ISRCTN50586181; http://www.isrctn.com/ISRCTN50586181

(J Med Internet Res 2020;22(7):e17571) doi: 10.2196/17571

\section{KEYWORDS}

smoking cessation; nicotine dependence; craving; virtual reality; mindfulness; digital therapy; mHealth; mobile phone

\section{Introduction}

\section{Background}

Tobacco use remains one of the biggest threats to public health and the leading preventable cause of mortality and morbidity worldwide [1]. Interventions on web-based platforms and mobile apps, among them smoking cessation apps, can deliver effective interventions for various diseases and behavioral disorders [2-16]. Smartphone-based smoking cessation apps can provide an important channel for offering interventions to the entire population [17]. However, participant adherence remains a challenge, and many of these apps struggle to maintain high levels of adherence, thus limiting their potential effectiveness [18].

In addition to smartphone-based interventions for smoking cessation, there have been promising developments in the use of virtual reality (VR). VR is defined as "real-time interactive graphics with [3-dimensional] models, combined with a display technology that gives the user the immersion in the model world and direct manipulation" [19]. The use of VR in digital medicine has been applied in consultancy and hospitals and accompanied by a health professional [20]. It has been demonstrated that the introduction of VR into treatment can improve patient engagement in a range of chronic disease interventions [21]. However, such technology has never been tested for tobacco use disorder as a self-assisted and remote solution to take advantage of the knowledge on how virtual environments can be used to elicit and reduce cravings and support smoking cessation.

Cravings are defined as intense urges or impulses for substance use [22] and are an essential component of substance use disorders, as they provoke drug-seeking behavior [23]. External cues can provoke cue-induced cravings [24] and thus provoke relapse $[25,26]$. Taken together, these findings suggest that craving is a critical target in the development of novel therapeutics for tobacco use disorder treatment [27,28].

Cue exposure therapy for substance use disorders involves controlled and repeated exposure to drug-related cues in order to extinguish cue-induced cravings [29], and VR technology is a potential mode of cue presentation [30,31]. Virtual reality exposure therapy (VRET) has already been used for smoking cessation [32,33], and studies have applied rigorous systematizations in VRET and cognitive behavioral therapy (CBT) [34-37], providing further evidence that this technique can reduce craving and smoking behavior, with similar effectiveness as stand-alone CBT.
Mindfulness is usually thought of as the awareness to attend to any thought, feeling, or sensation that occurs by simply acknowledging it, without attempting to regulate emotions [38]. Mindfulness training is already used in mobile health (mHealth) smoking cessation interventions [39] by teaching individuals to pay attention to the present moment, understand affective states and cravings to smoke as they appear, and consciously choose to let them pass without impulsively reacting to them. Preliminary evidence suggests that mindfulness-based interventions are associated with increased efficacy compared with other smoking cessation treatments [40,41]. Despite these promising results, in-person mindfulness training continues to present certain challenges. It requires experienced psychotherapists, increases time demands, limits access, and elevates costs [39].

\section{An Innovative Intervention: Mindcotine}

The aim of the current study was to develop an accessible and cost-effective digital intervention for smoking cessation that uses the latest technology adapted for large-scale use and to evaluate participant adherence and smoking cessation outcomes. Our novel intervention combines exposure to smoking-related cues in ecological situations using virtual reality and mindfulness as a tool to cope with in situ cravings, bodily sensations, affective states, and automatic reactions. The merge of these psychological frameworks are expected to work synergistically by reducing cravings. On the one hand, cue exposure treatment involves repeated exposure to smoking-related stimuli in order to elicit and, over time, extinguish cue-induced cravings. In addition, mindfulness techniques work on top of the immersive experience by helping the user to focus on cravings in the present moment. Mindfulness practice includes elements of acceptance and compassion through a perspective of curiosity towards the emerging sensations. Taken together, this intervention can help the user stay grounded in the present moment while acknowledging internal and external triggers. Moreover, these virtual reality and mindfulness sessions are part of a classic cognitive behavioral smoking cessation program that provides information on relevant topics daily through CBT notifications and community support among users moderated by psychologists and mindfulness facilitators. We hypothesized that this novel intervention approach would increase both adherence and abstinence rates among participating smokers compared to a treatment-as-usual control group. 


\section{Methods}

\section{Research Design}

The design of the study follows the recommendations for clinical trials in health using virtual reality, in particular, tier VR2 [42], focusing on acceptability, feasibility, tolerability, and initial clinical efficacy. We conducted a clinical trial with a control group, including baseline and follow-up assessments at days 1 and 90 posttreatment.

\section{Procedure}

The study was conducted from February to April of 2018 with a group of smokers from Buenos Aires, Argentina. The administration to the treatment group was carried out through an onboarding process that established the framework of the experience and the basic principles of the use of VR. The treatment was remotely self-administered through the use of a mobile app. The control group received a smoking cessation manual of the Argentine Ministry of Health.

The intervention group completed the onboarding process, which included digital informed consent, and received an intervention kit, which included guidelines that explained the use of the program, a unique ID to access the app, one cardboard headset, three stickers to announce smoke-free areas, and two wrist bracelets as a behavior replacement method that smokers could use to snap on their wrists when faced with a craving to smoke. Participants were also instructed to download the mobile app from the Google Play Store (Google Corp). The participants were trained in assembling the cardboard headset (see Multimedia Appendix 1) and app usability, and they completed the baseline assessment and received an explanation of the activities to be carried out during the 21-day intervention phase. The control group signed a digital informed consent sent to their emails and received the online version of the smoking cessation manual developed by the Office of the President of the Argentine Nation [43]. Intervention group participants received the first follow-up 1 day after they completed all 21 days of intervention content, which for some participants took longer than 21 days (postintervention follow-up) and another follow-up assessment at day 90 of posttreatment. Control group participants were assessed at days 30 and 90 after they had received the smoking cessation manual. All assessment invitations were sent via email and assessments were completed online using the Typeform (Typeform SL) platform. Figure 1 shows the participant flow diagram of the study. Participants did not receive any incentives. All study procedures were approved by the Institutional Review Board of the University of Flores, Buenos Aires, Argentina. The trial was registered in the International Standard Randomized Controlled Trial Number Registry (50586181). 
Figure 1. Participant flow through the Mindcotine method smoking cessation trial. TV: television; VR: virtual reality.

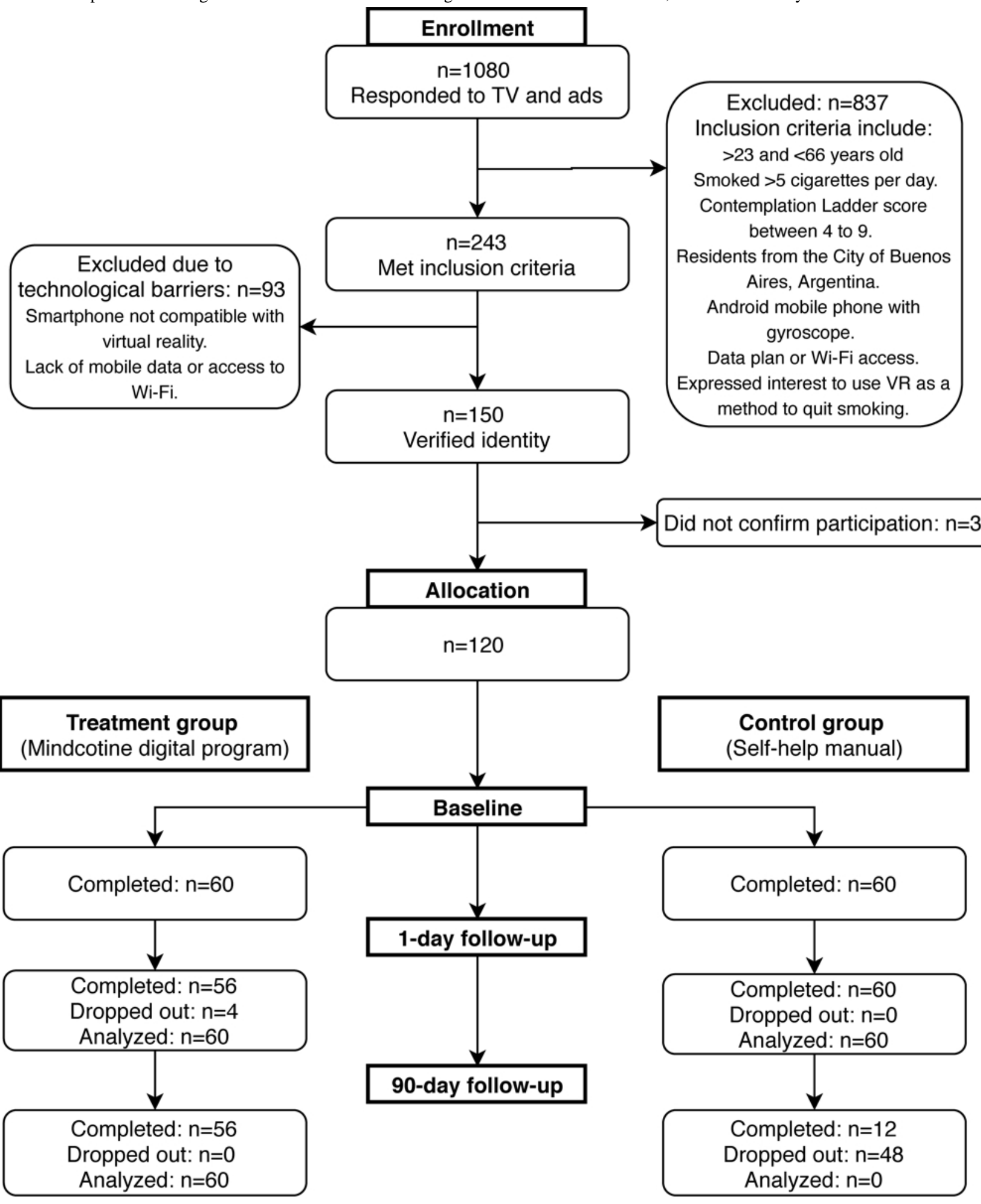

\section{Participants}

In order to be included in the study, the selected participants had to meet the following criteria: (1) be aged between 24 and 65 years, representing smokers with a high prevalence of daily smoking [44]; (2) consume a minimum of 5 cigarettes per day, with a score of 4 to 9 on the Contemplation Ladder [45]; (3) be residents in the city of Buenos Aires; (4) own an Android mobile phone with gyroscope; (5) have a data plan or Wi-Fi access; and (6) have an interest in using VR as a method to quit smoking. Each of these criteria was based on previous work with mobile apps for smoking cessation [46]. The one difference in our inclusion criteria compared with this existing research was that we also included smokers that scored below 7 on the Contemplation Ladder in order to investigate intervention effects for smokers not motivated to quit. Participants were excluded if they were diagnosed with a current psychiatric disorder.

For the recruitment of treatment and control group participants, unpaid advertisements were posted for 75 days on the 
Mindcotine page on Facebook, and a 13-minute segment was aired on Argentine national public television (channel C5N). The social network advertisements linked invitations directly to a screening questionnaire on the Typeform platform [47], which was completed by 1080 potentially eligible volunteers from all over Argentina. Of these initial applicants, 234 subjects lived in the city of Buenos Aires and fulfilled all other necessary inclusion criteria, and telephone contact was established to verify the data. A total of 150 participants were accepted after establishing contact and verifying their responses. However, 30 of these individuals did not confirm their participation, which resulted in a final sample of 120 volunteers. Participants were randomized into the treatment group $(\mathrm{TG})(\mathrm{n}=60)$ or control group (CG) (n=60) 1:1 using a blocked random assignment sequence. The treatment group was invited to the research site (University of Flores) and all participants signed an informed consent form, underwent the face-to-face onboarding process with one member of the study team, and were given the Mindcotine Kit to begin the study. The control group was contacted through email, provided digital informed consent, and received the online version of the smoking cessation manual by the Argentine Ministry of Health.

\section{Intervention}

The app consists of a 21-day treatment that includes 2 main activities each day, which become available after completing the activities of the previous day (see Figure 2). Intervention development was conducted iteratively using face-to-face testing and focus groups, with feedback from 250 smokers who tested the virtual reality environment of the intervention. Moreover, we reviewed existing smoking cessation apps and features related to trigger identification and reflective questions.

Figure 2. Mindcotine procedure flow diagram. 2D: 2-dimensional; CL: Contemplation Ladder; FFMQ: Five Facet Mindfulness Questionnaire; FTND: Fagerström Test of Nicotine Dependence; FU-90: 90-day follow-up; PI: postintervention; QSU: Questionnaire for Smoking Urges.

\begin{tabular}{|c|c|c|c|c|c|c|c|c|c|c|c|c|c|c|c|c|c|c|c|c|c|c|c|c|c|}
\hline \multicolumn{2}{|c|}{ Mindcotine's Procedure } & \multicolumn{10}{|c|}{ Days } \\
\hline Instrument & Format & 1 & 2 & 3 & 4 & 5 & 6 & 7 & 8 & 9 & 10 & 11 & 12 & 13 & 14 & 15 & 16 & 17 & 18 & 19 & 20 & 21 & PI & FU-90 \\
\hline CL & Questionnaire & $\checkmark$ & & & & & & & & & & & & & & & & & & & & & $\checkmark$ & \\
\hline QSU & Questionnaire & $\checkmark$ & & & & & & $\checkmark$ & & & & & & & $\checkmark$ & & & & & & & & $\checkmark$ \\
\hline FTND & Questionnaire & $\checkmark$ & & & & & & $\checkmark$ & & & & & & & $\checkmark$ & & & & & & & & $\checkmark$ & $\checkmark$ \\
\hline FFMQ & Questionnaire & $\checkmark$ & & & & & & & & & & & & & & & & & & & & & $\checkmark$ & $\checkmark$ \\
\hline Daily self-registration & Daily questionnaire & $\checkmark$ & $\checkmark$ & $\checkmark$ & $\checkmark$ & $\checkmark$ & $\checkmark$ & $\checkmark$ & $\checkmark$ & $\checkmark$ & $\checkmark$ & $\checkmark$ & $\checkmark$ & $\checkmark$ & $\checkmark$ & $\checkmark$ & $\checkmark$ & $\checkmark$ & $\checkmark$ & $\checkmark$ & $\checkmark$ & $\checkmark$ & $\checkmark$ & $\checkmark$ \\
\hline Mindfulness sessions & Audio & $\checkmark$ & $\checkmark$ & $\checkmark$ & $\checkmark$ & $\checkmark$ & $\checkmark$ & $\checkmark$ & $\checkmark$ & $\checkmark$ & $\checkmark$ & $\checkmark$ & $\checkmark$ & $\checkmark$ & $\checkmark$ & $\checkmark$ & $\checkmark$ & $\checkmark$ & $\checkmark$ & $\checkmark$ & $\checkmark$ & $\checkmark$ & $\checkmark$ & \\
\hline Formal mindfulness & 2D session & $\checkmark$ & $\checkmark$ & $\checkmark$ & $\checkmark$ & $\checkmark$ & $\checkmark$ & & & & & & & & & & & & & & & & \\
\hline Informal mindfulness & Virtual reality session & & & & & & & $\checkmark$ & $\checkmark$ & $\checkmark$ & $\checkmark$ & $\checkmark$ & $\checkmark$ & $\checkmark$ & $\checkmark$ & $\checkmark$ & $\checkmark$ & $\checkmark$ & $\checkmark$ & $\checkmark$ & $\checkmark$ & $\checkmark$ & \\
\hline Community chat & Chat & $\checkmark$ & $\checkmark$ & $\checkmark$ & $\checkmark$ & $\checkmark$ & $\checkmark$ & $\checkmark$ & $\checkmark$ & $\checkmark$ & $\checkmark$ & $\checkmark$ & $\checkmark$ & $\checkmark$ & $\checkmark$ & $\checkmark$ & $\checkmark$ & $\checkmark$ & $\checkmark$ & $\checkmark$ & $\checkmark$ & $\checkmark$ & $\checkmark$ \\
\hline Mindcotine support & SMS and phone calls & & & $\checkmark$ & $\checkmark$ & $\checkmark$ & $\checkmark$ & $\checkmark$ & $\checkmark$ & $\checkmark$ & $\checkmark$ & $\checkmark$ & $\checkmark$ & $\checkmark$ & $\checkmark$ & $\checkmark$ & $\checkmark$ & $\checkmark$ & $\checkmark$ & $\checkmark$ & $\checkmark$ & $\checkmark$ & $\checkmark$ \\
\hline
\end{tabular}

The elements of the program were (1) practice sessions in formal mindfulness, (2) practice sessions in informal mindfulness using virtual reality mindful exposure therapy (VR-MET), (3) daily self-reports, (4) peer-to-peer support, and (5) Mindcotine support.

First, practice sessions in formal mindfulness included 6 sessions of mindfulness in video format of up to 10 minutes each and 7 sessions in audio format of 3 to 10 minutes each. These were based on the works of Kabat-Zinn [48] and Bowen and Marlatt [40], where the user is given an initial introduction to mindfulness involving the recognition of bodily sensations and the ability to practice nonreactivity to emotions and thoughts related to smoking, from a compassionate and nonjudgmental position.

Second, practice sessions in informal mindfulness using VR included 2 sessions of VR-MET, each lasting 10 minutes. These sessions included a selection of 2 virtual environments that combined the awareness of the act of smoking and the recognition of craving from a perspective of acceptance and commitment. This selection is the result of an adaptation of the previously conducted work synthesized by Brewer [49] and included virtual environments used in cue exposure therapy. Regarding VR-MET design, each of the virtual environments was created based on previous research that proved the environment to elicit craving [50] and was recorded with an Insta360Pro camera (Insta360) [51] in locations in Mexico City, Mexico, and Buenos Aires, Argentina. The animated parts of the environments were created in Unreal Engine 4 (Epic Games) and based on previous research to induce emotional states of tranquility and relaxation [52] (see Multimedia Appendix 2). The mindfulness audio from both environments was chosen to work consciously with craving-related acts ("RAIN": Recognize, Accept, Investigate and Nourish, and "Act of Smoking": consciously review each moment of the act itself). Each video was repeated over a period of 14 consecutive days, based on previous research regarding the time of exposure in virtual environments and the time between the exposures $[30,34,37,53]$.

Third, daily self-reports were included. At the end of the day, each user reported on the app their total daily number of cigarettes, reasons that any cravings were triggered, and a written answer to the question "What do you think has changed in your relationship to smoking as of today?" (nightly reflections). This data was collected on the Typeform platform embedded in the app.

Fourth, peer-to-peer support was provided via the app's group chat feature for interacting with all other participants. The group 
chat was moderated by a psychologist and a mindfulness facilitator to promote engagement and respond to participant questions.

Fifth, Mindcotine support could be prompted. If participants were inactive for a certain amount of time, they received a text message (after 2 days) and a phone call (after 4 days) to encourage engagement within the program. Participants could contact Mindcotine for technical support by email anytime as well.

These components can be seen in Figure 3 (mindfulness exercises), Figure 4 (nightly reflection), Figure 5 (dashboard), and Figure 6 (VR-MET).

Figure 3. App screenshot of the home screen showing mindfulness activities.

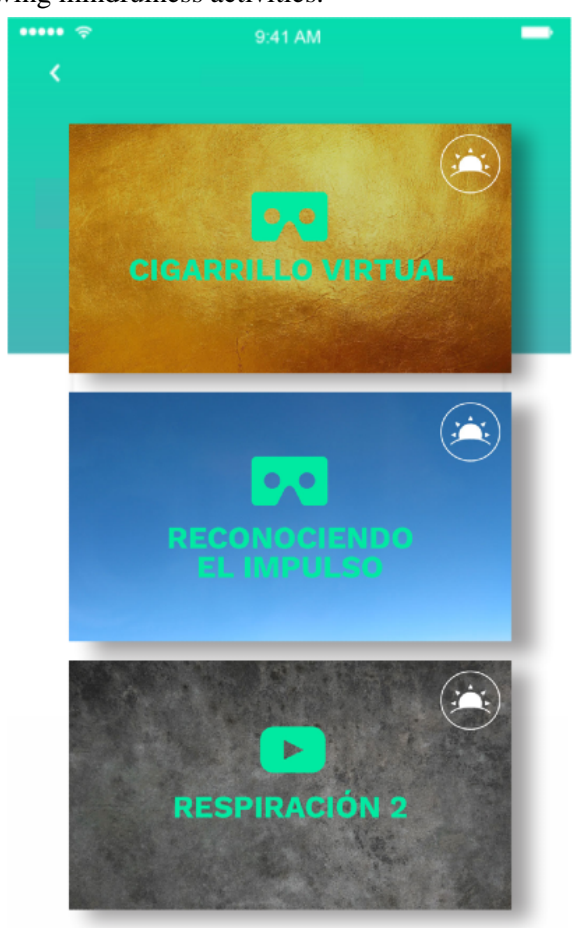

Figure 4. App screenshot of the nightly reflection.

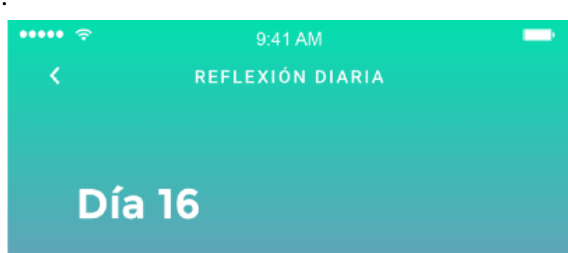

¿Cuántos cigarrillos consumiste hoy?

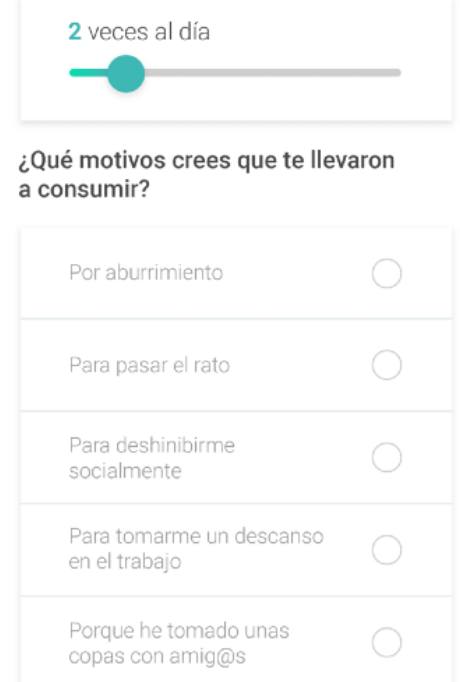


Figure 5. App screenshot on the dashboard showing statistics about money and the number of smoked cigarettes.

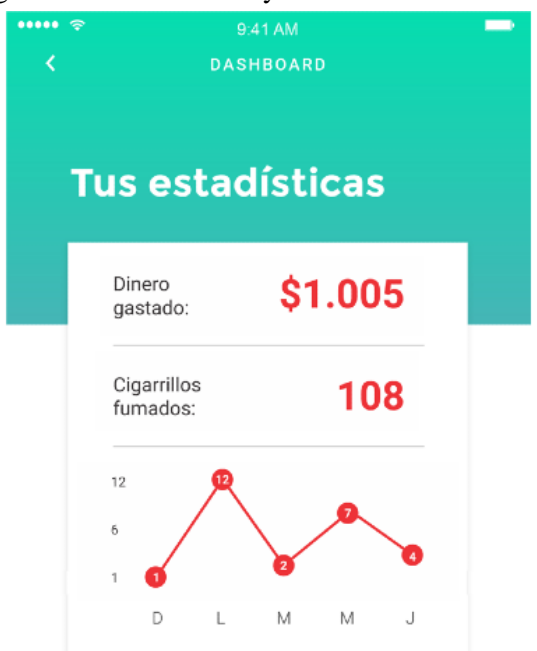

Tu progreso

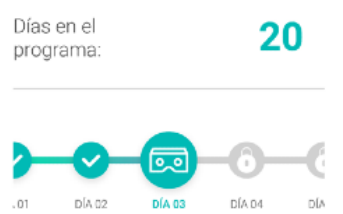

Figure 6. Virtual reality mindful exposure therapy screenshot: Act of Smoking.

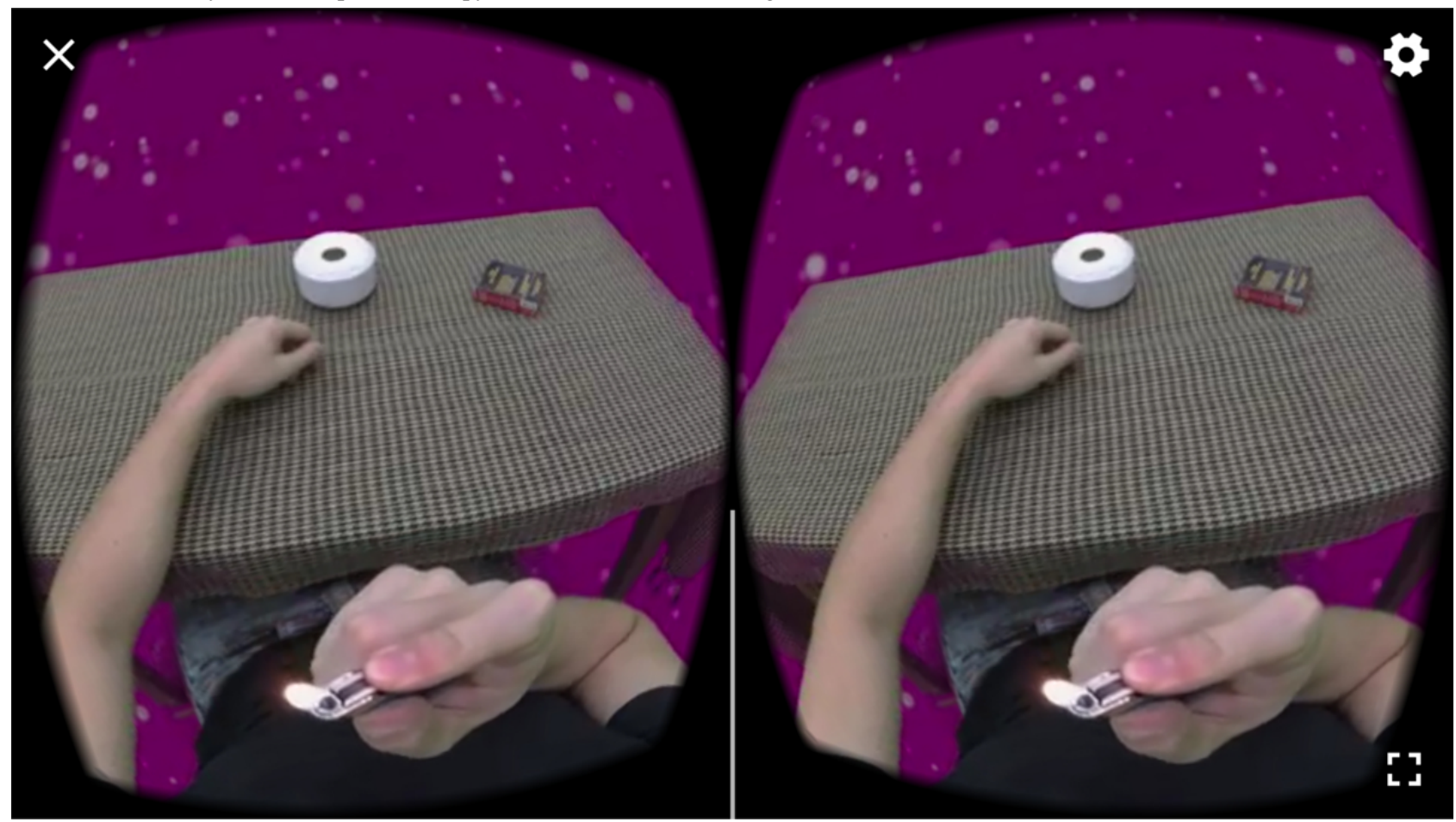

\section{Measures}

\section{Baseline Assessment}

The baseline assessment was conducted on the app and included demographic data (age, gender, education), smoking behavior (number of cigarettes per day, years of smoking, previous cessation attempts, readiness to quit), characteristics of the environment and family context (marital status, children, living with smokers), and other health-related characteristics (body mass index, physical activity, previous meditation experience).

\section{Primary Outcome}

The primary outcome was self-reported abstinence at postintervention, assessed 1 day after the end of the program. The question used for assessment was "Did you smoke tobacco in the last 24 hours?" 


\section{Secondary Outcomes}

\section{Sustained Abstinence}

Sustained abstinence was self-reported abstinence at 90 days after the end of the program in the TG. The question used for assessment was "Did you smoke tobacco in the last 90 days?"

\begin{abstract}
Adherence
Adherence was assessed using log file data collected by employing the platform Amplitude (Amplitude Inc) [54], which measured total use of the app for each participant. Adherence to treatment was categorized as the percentage of participants who completed all daily activities and all daily diary questionnaires throughout the intervention with intervals of discontinuity no greater than 4 consecutive days. We operationalized full adherence as to whether or not the participant completed the treatment in the suggested time (ie, 21 days without any breaks), regular adherence as whether participants completed all daily activities in up to 60 days, and depth of adherence as the total number of mindfulness training minutes [55]. Chat room activity beyond the initial onboarding post was measured by the number of participant comments in the chat room and dichotomized to any activity versus no activity.
\end{abstract}

\section{Cigarette Consumption}

Participants were instructed to report the number of cigarettes they smoked each day during treatment as part of their daily self-reports, at postintervention, and at 90-day follow-up. Over the treatment period, the daily number of cigarettes was stored and averaged per week.

\section{Craving}

Craving was assessed using the Questionnaire for Smoking Urges (QSU) [56], which consists of a 7-point Likert scale. These data were collected through an online survey at baseline, at the end of days 7 and 14, and at postintervention. The internal consistency for the overall scale was adequate $(\alpha=.87)$.

\section{Mindfulness}

Mindfulness was assessed using the Five Facet Mindfulness Questionnaire (FFMQ) [57]. The 5 dimensions are observing, describing, acting with awareness, not judging internal experience, and not reacting to internal experience. These data were collected through an online survey at baseline, at postintervention, and at 90-day follow-up.

\section{Readiness to Quit}

Readiness to quit was assessed using the Contemplation Ladder [45], which consists of 11 rungs and 5 anchor statements reflecting the stages of change and was designed to measure readiness to quit smoking. It was assessed through an online survey at baseline and at postintervention.

\section{Nicotine Dependence}

Nicotine dependence was assessed using the Fagerström Test of nicotine dependence [58], which consists of a 6-item self-report scale and observes responses suggestive of physiological dependence on nicotine. These data were collected through an online survey at the beginning of the program, at the end of day 7, day 14, postintervention, and 90-day follow-up. The internal consistency for the overall scale was adequate $(\mathrm{a}=.81)$.

\section{Data Analysis}

Statistical analysis was performed with SPSS for Windows (version 22; IBM Corp). Abstinence rates between groups were compared using a chi-square test. Participants with missing data at follow-up were assumed to be smoking. Repeated measure analyses of variance (ANOVAs) were used to determine between-group differences and intervention effects for continuous variables. The group factor had 2 levels, corresponding to intervention and control group, and the time factor had 3 levels, corresponding to the 3 assessment points (baseline, postintervention, and 90-day follow-up). Post hoc analyses were conducted to determine significant pairwise comparisons. ANOVAs and post hoc tests were conducted to determine changes within the treatment group over time. All $t$ tests in the study were 2-tailed.

\section{Results}

\section{Recruitment and Participation in the Intervention}

Participant baseline characteristics are displayed in Table 1. On average, participants in the sample were 43.25 years old (SD $10.06)$ and $47.5 \%(57 / 120)$ were female. The largest group in terms of completed educational level was high school (45/120, $37.5 \%)$, followed by university $(43 / 120,35.8 \%)$. On average, the sample started smoking 19.15 years ago (SD 12.35) and consumed an average of 10.77 (SD 5.47) cigarettes per day. Of all participants, $14.2 \%(17 / 120)$ lived with other smokers in their homes. The entire sample reported a moderated nicotine dependence index, based on the mean scores obtained in the Fagerström Nicotine Dependence Test [58], of 4.48 (SD 1.55). Only $40.8 \%$ (49/120) had practiced meditation at least once in their life. No statistically significant differences were observed between treatment and control group on any variables at baseline. 
Table 1. Participant baseline characteristics $(\mathrm{N}=120)$.

\begin{tabular}{|c|c|c|c|}
\hline Characteristics & Full sample $(\mathrm{N}=120)$ & Treatment group $(n=60)$ & Control group $(n=60)$ \\
\hline Age (years), mean (SD) & $43.25(10.06)$ & $44.06(9.89)$ & $42.44(10.23)$ \\
\hline Gender (female), n (\%) & $57(48)$ & $33(55)$ & $24(41)$ \\
\hline \multicolumn{4}{|l|}{ Education, $\mathbf{n}(\%)$} \\
\hline $\mathrm{PhD}$ or higher & $9(8)$ & $7(11)$ & $2(5)$ \\
\hline University & $43(36)$ & $25(38)$ & $18(30)$ \\
\hline Undergraduate & $10(8)$ & $3(3)$ & $7(6)$ \\
\hline Technical & $6(5)$ & $3(3)$ & $3(8)$ \\
\hline High school & $45(38)$ & $19(28)$ & $26(44)$ \\
\hline Primary school & $7(6)$ & $3(5)$ & $4(6)$ \\
\hline Years since started smoking, mean (SD) & $19.15(12.35)$ & $19.40(12.28)$ & $18.91(12.42)$ \\
\hline Current cigarette consumption (cigarettes per day), mean (SD) & $10.77(5.47)$ & $11.09(5.27)$ & $10.45(5.67)$ \\
\hline At least 1 attempt to quit in the last year, $\mathrm{n}(\%)$ & $65(54)$ & $32(53)$ & $33(55)$ \\
\hline Live with other smokers, $\mathrm{n}(\%)$ & $17(14)$ & $10(17)$ & $7(12)$ \\
\hline Nicotine dependence $\left(\mathrm{FTND}^{\mathrm{a}}\right)$, mean (SD) & $4.48(1.55)$ & $4.22(1.51)$ & $4.75(1.56)$ \\
\hline Craving $\left(\mathrm{QSU}^{\mathrm{b}}\right)$, mean $(\mathrm{SD})$ & $29.5(9.67)$ & $30.28(11.72)$ & $28.71(7.08)$ \\
\hline Readiness to quit (Contemplation Ladder), mean (SD) & $6.68(1.17)$ & $6.53(1.14)$ & $6.83(1.18)$ \\
\hline Precontemplation, $\mathrm{n}(\%)$ & $5(4)$ & $2(3)$ & $3(5)$ \\
\hline Contemplation, n (\%) & $45(38)$ & $26(43)$ & $19(32)$ \\
\hline Preparation, n (\%) & $67(56)$ & $31(52)$ & $36(60)$ \\
\hline Action, $\mathrm{n}(\%)$ & $3(3)$ & $1(2)$ & $2(3)$ \\
\hline No experience in meditation, $\mathrm{n}(\%)$ & $71(59)$ & $33(54)$ & $38(64)$ \\
\hline Five Facet Mindfulness Questionnaire, mean (SD) & $123.16(8.73)$ & $123.94(9.55)$ & $122.43(7.83)$ \\
\hline
\end{tabular}

${ }^{\mathrm{a}}$ FTND: Fagerström Test of Nicotine Dependence.

${ }^{\mathrm{b}} \mathrm{QSU}$ : Questionnaire for Smoking Urges.

\section{Primary Outcomes}

At postintervention, the TG reported 23\% (14/60) abstinence on that day compared with 5\% (3/60) of the CG. This difference was statistically significant $\left(\chi_{1}^{2}=8.3 ; P=.004\right)$.

\section{Secondary Outcomes}

\section{Sustained Abstinence}

The TG reported 33\% (20/60) sustained abstinence on the 90-day follow-up, compared with 5\% (3/60) of participants in the CG. Since only $20 \%(12 / 60)$ of participants in the CG completed the 90-day follow-up, we did not conduct a statistical comparison between groups at this follow-up time point.

\section{Adherence Rates}

Intervention adherence was analyzed only in the TG, and $93 \%$ (56/60) of participants finished the 21-day program. Of those who finished, $41 \%(23 / 56)$ were fully adherent to the program (ie, completed all daily sessions and nightly reflections 21 days in a row) and 59\% (33/56) were regularly adherent (ie, completed the program in $>21$ days), completing the program in 28.56 days on average. At the postintervention, $30 \%(7 / 23)$ of fully adherent participants reported smoking abstinence, while only $21 \%(7 / 33)$ of regularly adherent participants were abstinent. At the 90-day follow-up, smoking abstinence rates were 39\% (9/23) among fully adherent participants and 33\% (11/33) among regularly adherent participants. A statistically significant difference in readiness to quit was found between the fully and the regularly adherent group at baseline $\left(\mathrm{t}_{55}=3.092\right.$; $P=.003$ ), with fully adherent participants reporting greater readiness to quit. No differences were found regarding nicotine dependence $\left(\mathrm{t}_{55}=1.206 ; P=.23\right)$ at baseline, nor regarding abstinence rates between the 2 adherence groups at postintervention $\left(\chi_{1}^{2}=6.1 ; P=.43\right)$ and at 90-day follow-up $\left(\chi_{1}^{2}=1.9 ; P=.66\right)$

If participants had not engaged with the program for 2 subsequent days, they were contacted in order to improve engagement. A total of $92 \%(54 / 60)$ of participants were contacted through SMS text messaging once; 65\% (39/60), twice; 53\% (32/60), thrice; and 34\% (20/60) were contacted through both SMS text messaging and phone call reminders. Depth of adherence for all participants, measured by the number of minutes of mindfulness training during the program (including virtual reality, video format, and audio format), was 
259.05 minutes on average, with a maximum of 386 minutes and a minimum of 216 minutes.

For those who reported abstinence at postintervention, the average mindfulness minutes trained was 250.43 minutes, while the average was 261.93 minutes among those who continued smoking. Statistically significant differences were not found between groups $\left(\mathrm{t}_{55}=-1.291 ; P=.20\right)$.

Participant activity in the chat room beyond an initial introduction message suggested in the onboarding process was low and only 13 participants commented in the chat room beyond the onboarding. Chat room activity was not associated with smoking cessation outcomes, having only 1 participant that successfully quit smoking while being active in the chat.

\section{Cigarette Consumption}

Statistically significant differences in cigarettes per day over time were found between the TG and the CG $\left(F_{5,114}=95.73\right.$; $P<.001)$ in the third week of the intervention and at postintervention. At intervention week 3 , the TG consumed significantly fewer cigarettes than the CG (TG: mean 6.92, SD 5.26; CG: mean 9.03, SD 5.42; $P=.03$ ). Significant differences in cigarettes per day between groups were also found at postintervention (TG: mean 5.07, SD 5.65; CG: mean 9.53, SD $0.56 ; P<.001)$

\section{Readiness to Quit}

The means comparison in the Contemplation Ladder for the TG and the $\mathrm{CG}$ showed statistically significant differences between groups $\left(F_{2,113}=4.55 ; P=.01\right)$. Post hoc comparisons revealed that there were no differences at baseline (TG: mean 6.53, SD 0.14; CG: mean 6.83 , SD $0.18 ; P=.32$ ), but there were at postintervention (TG: mean 7.71, SD 0.13; CG: mean 7.16, SD $0.13 ; P=.005)$.

\section{Mean Differences Within the Treatment Group Over Time}

\section{Cigarette Consumption}

Post hoc tests after ANOVA were conducted for cigarette consumption, and statistically significant differences over time were found within the TG $\left(F_{4,52}=13.79 ; P<.001\right)$. Participants significantly reduced their cigarettes per day from baseline (mean 11.09, SD 5.27) to postintervention (mean 6.05, SD 5.67; $P<.001$ ), as well as from baseline to 90 -day follow-up (mean 5.07, SD 5.65; $P<.001)$.

\section{Mindfulness}

Moreover, according to paired $t$ test comparisons for FFMQ scores, no statistically significant difference was found between baseline (mean 123.95, SD 9.55) and postintervention (mean 122.61, SD 6.31; $\left.\mathrm{t}_{55}=0.772 ; P=.44\right)$. However, FFMQ at 90 -day follow-up (mean 115.89, SD 12.30) was significantly lower than scores at baseline $\left(\mathrm{t}_{55}=5.594 ; P<.001\right)$ and postintervention $\left(\mathrm{t}_{55}=3.234 ; P=.002\right)$.

\section{Craving}

A significant reduction in self-reported craving over time was observed in the treatment group (baseline: mean 30.28, SD
11.72; intervention week 1: mean 30.01, SD 11.75; intervention week 2: mean 28.00, SD 13.00; postintervention: mean 26.00, SD 11.37). These differences over time were statistically significant $\left(F_{1,24}=3.725 ; P=.005\right)$.

\section{Discussion}

\section{Principal Findings}

This is the first study to report results of a pilot trial testing a VR smartphone-based smoking cessation program using remote and self-assisted delivery. At postintervention, the intervention group had a significantly higher abstinence rate (14/60, 23\% abstinence) compared with the control group, which received a smoking cessation manual (3/60, 5\% abstinence). Moreover, the intervention resulted in a 33\% (20/60) abstinence rate at 90-day follow-up and high levels of adherence and engagement. Findings suggest the potential efficacy of a smartphone-based VR intervention that combines exposure therapy and mindfulness for smoking cessation.

When compared with other smoking cessation app studies, abstinence rates observed in the current study were in a similar range. For instance, an 8-week single-arm trial of a smartphone app that delivered essential features of US clinical practice guidelines with personalization resulted in a $26 \%$ abstinence rate at 30-day follow-up [59]. Another single-arm trial based on acceptance and commitment therapy had abstinence rates of $33 \%$ at 7-day follow-up and $28 \%$ at 30-day follow-up [60]. These rates are similar to the $23 \%(14 / 60)$ and $33 \%(20 / 60)$ observed in our study and provide confidence for further development and testing.

With 93\% (56/60) of participants finishing the 21-day program, the current study had a high completion and low dropout rate. In line with other studies, we used several strategies to enhance adherence, including SMS text messaging and phone call reminders [55]. Consistent with our findings, adherence rates were also above $80 \%$ in the above-mentioned 8-week single-arm clinical trial [59] and in a randomized controlled trial of a text messaging program [61]. Of all $56 \mathrm{TG}$ participants who finished the program, 23 completed without any gaps in treatment adherence and were classified as fully adherent, while the other 33 participants took an average of 28.56 days to complete the program and were classified as regularly adherent. The fully adherent group reported greater readiness to quit at baseline. Abstinence at postintervention and 90-day follow-up was higher among fully adherent participants compared with regularly adherent participants. These findings suggest that repeated exposure to smoking-related cues in virtual environments alongside mindfulness practice on a consecutive daily basis may increase abstinence outcomes compared with sessions that are more spaced out over time. Thus, a more consistent and disciplined training using virtual reality mindfulness-based exposure therapy to both internal and external triggers over a shorter period of time may result in better outcomes. Based on other studies [62], the chat room activity was low probably due to the lack of promotion to increase engagement through tailored material by the moderators. Overall, the methods used to strengthen engagement have been shown to have value and can be further developed. 
Our results also indicate that mindfulness scores measured by the FFMQ significantly decreased within the TG from baseline to 90-day follow-up. It is unclear what may have caused this decrease despite the promising smoking cessation outcomes of our intervention. Given that the current study is the first to combine virtual reality exposure therapy and mindfulness-based relapse prevention for smoking cessation, replication of these findings is needed. Moreover, future studies should further explore the mechanisms of action of this novel intervention approach.

Other studies using VR and exposure therapy in smoking cessation showed similar results in decreasing cue-induced craving, such as a randomized clinical trial that combined CBT and virtual reality cue exposure therapy (VR-CET), which found a significant reduction of cue-induced cravings after group-based sessions over the course of 6 months with 5 individual sessions of VR-CET [37]. In the current study, the virtual reality environments exposed participants to smoking-related cues and at the same time presented a mindfulness narrative based on relapse prevention. Therefore, the intervention simultaneously elicits cravings by means of VRET and provides the user with tools for reducing these cravings by means of mindfulness. Our results of QSU craving scores over time show that scores did not decrease during the first week of treatment, in which there was no exposure therapy. However, self-reported cravings decreased during the following 14 days of the program, in which VR-MET was delivered.

Feasibility of conducting the trial was demonstrated by the fact that we were able to recruit 120 participants in the current pilot trial. However, feasibility of collecting follow-up data from a control group needs to be improved. The delivery of the intervention was feasible and acceptable to participants; $41 \%$ (23/56) of intervention participants completed the entire intervention content in 21 days, as recommended, and the average adherence to mindfulness training was 259.05 minutes per participant. Feasibility of the VR component as a central element of the program was high, with all participants practicing at least 15 informal mindfulness practice sessions lasting 10 minutes each. Even though this intervention introduced VR and mindfulness training to a population that had almost never tried any of these approaches before, the intervention had high engagement rates, suggesting remote and self-administered VR can be used as a strategy for improving adherence to mHealth interventions. These findings are in line with those of existing studies, which have shown that VR can enhance treatment fidelity by having behavioral interventions delivered by a programmed avatar [21] and that VR environments offer existing opportunities to enhance a patient's involvement in treatments [63].

Given that VR in mental health to date has predominantly been used in inpatient hospital environments [20], the recruitment method used in the current study to test the potential of VR as a self-administered and remote smoking cessation intervention on an outpatient population is worth mentioning. After appearing on national television, more than 1000 volunteers from all over Argentina registered within a few hours. The average age of these volunteers was 41 years, which was considerably older than we had anticipated. The fact that we were able to recruit this population for a smartphone-based smoking cessation study using a VR cardboard headset demonstrates that this intervention can be accessible to populations that do not need to be exceptionally tech savvy. In light of existing challenges to recruit participants for mHealth interventions [64], this particular recruitment strategy may prove valuable for future research.

The creation of Mindcotine involved a group of psychologists, psychiatrists, and other physicians, as well as developers, actors, and mindfulness facilitators, and took over 6 months. While initial development costs were high, the fact that this program can be delivered remotely and self-administered makes it a low-cost and accessible intervention to promote smoking cessation.

\section{Limitations}

The current study has several limitations. The follow-up time was relatively short, given that only between $3 \%$ and $5 \%$ of smokers remain abstinent within the first year of quitting [65]. Follow-up assessment time points were not identical across intervention and control groups. Before the current pilot trial, we did not know how long participants would take to complete the entire program, thus we selected a 30-day follow-up time point for the control group. Future research will adhere to a consistent follow-up assessment time point across intervention and control groups. Completion of the 90-day follow-up in the control group was low. It is possible that control group participants may not have been motivated to complete follow-up surveys due to not seeing changes in their behavior, not receiving a digital intervention, or not receiving any monetary incentive. Control group follow-up rates need to be improved in future trials of this intervention. Other limitations include that at baseline, participants were not regular users of VR, the virtual intervention content was not interactive, only an Android version of the intervention app was available, and the version of the intervention tested in the current study did not include features for the users to track cravings on the app and in virtual reality environments. These features are currently in development for future versions of the intervention. Moreover, abstinence at follow-up was self-reported and subsequent investigations should include biochemical verification of outcomes.

Finally, the face-to-face meeting and the onboarding process at the beginning of the program could have impacted the high adherence rates observed in this trial and online onboarding may work differently. Future studies should administer the entire program remotely.

\section{Conclusion}

Overall, our VR smartphone-based Mindcotine intervention to support smoking cessation showed great potential with regard to participant adherence and initial efficacy. These findings warrant testing the intervention in a fully powered randomized trial including longer follow-up intervals to investigate relapse prevention and biochemical verification of abstinence. 


\section{Acknowledgments}

This research was supported financially by the University of Flores (internal protocol number 17EX04), by a grant received from the Argentine Ministry of Production (Seed Fund project number 3291022226), and through sponsorship by MindCotine Inc.

\section{Authors' Contributions}

EG and MRC participated in the study design. NR and CW participated in the data collection process. JU participated in the data analysis. MRC, EG, and JT participated in the interpretation of data. EG and JT wrote the first draft of the manuscript. All authors participated in revising the manuscript.

\section{Conflicts of Interest}

JT's contribution to this publication was as a member of the Advisory Board of MindCotine Inc. This arrangement has been reviewed and approved by the Johns Hopkins University in accordance with its conflicts of interest policies. EG, NR, and CW have shares in MindCotine Inc, the company that developed the VR environments and the app for this study. JU and MRC have no conflicts of interest.

\section{Multimedia Appendix 1}

Instructional video. How to assemble the virtual reality headset.

[MP4 File (MP4 Video), 7676 KB-Multimedia Appendix 1]

\section{Multimedia Appendix 2}

Brief VR-MET environment.

[MP4 File (MP4 Video), 26023 KB-Multimedia Appendix 2]

\section{Multimedia Appendix 3}

CONSORT-eHEALTH checklist (V 1.6.1).

[PDF File (Adobe PDF File), 2557 KB-Multimedia Appendix 3]

\section{References}

1. World Health Organization. WHO Report on the Global Tobacco Epidemic, 2017: monitoring tobacco use and prevention policies. World Health Organization. Geneva, Switzerland: World Health Organization; 2017. URL: https://apps.who.int/ iris/bitstream/handle/10665/255874/9789241512824-eng.pdf [accessed 2020-06-29]

2. Strecher VJ, Shiffman S, West R. Randomized controlled trial of a web-based computer-tailored smoking cessation program as a supplement to nicotine patch therapy. Addiction 2005 May;100(5):682-688. [doi: 10.1111/j.1360-0443.2005.01093.x] [Medline: 15847626]

3. Tufano JT, Karras BT. Mobile eHealth interventions for obesity: a timely opportunity to leverage convergence trends. J Med Internet Res 2005 Dec 20;7(5):e58 [FREE Full text] [doi: 10.2196/jmir.7.5.e58] [Medline: 16403722]

4. Smith D, Griffiths E, Poole R, di Florio A, Barnes E, Kelly M, et al. Beating Bipolar: exploratory trial of a novel Internet-based psychoeducational treatment for bipolar disorder. Bipolar Disord 2011;13(5-6):571-577. [doi: 10.1111/j.1399-5618.2011.00949.x] [Medline: 22017225]

5. Spring B, Schneider K, McFadden HG, Vaughn J, Kozak AT, Smith M, et al. Multiple behavior changes in diet and activity: a randomized controlled trial using mobile technology. Arch Intern Med 2012 May 28;172(10):789-796 [FREE Full text] [doi: 10.1001/archinternmed.2012.1044] [Medline: 22636824]

6. Whittaker R, McRobbie H, Bullen C, Borland R, Rodgers A, Gu Y. Mobile phone-based interventions for smoking cessation. Cochrane Database Syst Rev 2012 Nov 14;11:CD006611. [doi: 10.1002/14651858.CD006611.pub3] [Medline: 23152238]

7. Lin Y, Tudor-Sfetea C, Siddiqui S, Sherwani Y, Ahmed M, Eisingerich AB. Effective Behavioral Changes through a Digital mHealth App: Exploring the Impact of Hedonic Well-Being, Psychological Empowerment and Inspiration. JMIR Mhealth Uhealth 2018 Jun 15;6(6):e10024 [FREE Full text] [doi: 10.2196/10024] [Medline: 29907557]

8. Lyons EJ, Lewis ZH, Mayrsohn BG, Rowland JL. Behavior change techniques implemented in electronic lifestyle activity monitors: a systematic content analysis. J Med Internet Res 2014 Aug 15;16(8):e192 [FREE Full text] [doi: 10.2196/jmir.3469] [Medline: 25131661]

9. Brendryen H, Kraft P. Happy ending: a randomized controlled trial of a digital multi-media smoking cessation intervention. Addiction 2008 Mar;103(3):478-84; discussion 485. [doi: 10.1111/j.1360-0443.2007.02119.x] [Medline: 18269367]

10. Riley W, Obermayer J, Jean-Mary J. Internet and mobile phone text messaging intervention for college smokers. J Am Coll Health 2008;57(2):245-248. [doi: 10.3200/JACH.57.2.245-248] [Medline: 18809542$]$

11. Fjeldsoe BS, Marshall AL, Miller YD. Behavior change interventions delivered by mobile telephone short-message service. Am J Prev Med 2009 Feb;36(2):165-173. [doi: 10.1016/j.amepre.2008.09.040] [Medline: 19135907] 
12. Webb TL, Joseph J, Yardley L, Michie S. Using the internet to promote health behavior change: a systematic review and meta-analysis of the impact of theoretical basis, use of behavior change techniques, and mode of delivery on efficacy. J Med Internet Res 2010 Feb 17;12(1):e4 [FREE Full text] [doi: 10.2196/jmir.1376] [Medline: 20164043]

13. Cole-Lewis H, Kershaw T. Text messaging as a tool for behavior change in disease prevention and management. Epidemiol Rev 2010;32:56-69 [FREE Full text] [doi: 10.1093/epirev/mxq004] [Medline: 20354039]

14. Rotondi AJ, Anderson CM, Haas GL, Eack SM, Spring MB, Ganguli R, et al. Web-based psychoeducational intervention for persons with schizophrenia and their supporters: one-year outcomes. Psychiatr Serv 2010 Nov;61(11):1099-1105. [doi: 10.1176/ps.2010.61.11.1099] [Medline: 21041348]

15. Free C, Knight R, Robertson S, Whittaker R, Edwards P, Zhou W, et al. Smoking cessation support delivered via mobile phone text messaging (txt2stop): a single-blind, randomised trial. Lancet 2011 Jul 02;378(9785):49-55 [FREE Full text] [doi: 10.1016/S0140-6736(11)60701-0] [Medline: 21722952]

16. Riley WT, Rivera DE, Atienza AA, Nilsen W, Allison SM, Mermelstein R. Health behavior models in the age of mobile interventions: are our theories up to the task? Transl Behav Med 2011 Mar;1(1):53-71 [FREE Full text] [doi: 10.1007/s13142-011-0021-7] [Medline: 21796270]

17. Zeng EY, Vilardaga R, Heffner JL, Mull KE, Bricker JB. Predictors of Utilization of a Novel Smoking Cessation Smartphone App. Telemed J E Health 2015 Dec;21(12):998-1004 [FREE Full text] [doi: 10.1089/tmj.2014.0232] [Medline: 26171733]

18. Abroms LC, Lee Westmaas J, Bontemps-Jones J, Ramani R, Mellerson J. A content analysis of popular smartphone apps for smoking cessation. Am J Prev Med 2013 Dec;45(6):732-736 [FREE Full text] [doi: 10.1016/j.amepre.2013.07.008] [Medline: 24237915]

19. Bishop G, Fuchs H. Research directions in virtual environments. SIGGRAPH Comput Graph 1992 Aug;26(3):153-177. [doi: $\underline{10.1145 / 142413.142416]}$

20. Dascal J, Reid M, IsHak WW, Spiegel B, Recacho J, Rosen B, et al. Virtual Reality and Medical Inpatients: A Systematic Review of Randomized, Controlled Trials. Innov Clin Neurosci 2017;14(1-2):14-21 [FREE Full text] [Medline: 28386517]

21. Coons MJ, Roehrig M, Spring B. The potential of virtual reality technologies to improve adherence to weight loss behaviors. J Diabetes Sci Technol 2011 Mar 01;5(2):340-344 [FREE Full text] [doi: 10.1177/193229681100500221] [Medline: 21527103]

22. American Psychiatric Association. Diagnostic and Statistical Manual of Mental Disorders, 5th Edition (DSM-5). Washington, DC: American Psychiatric Publishing; 2013.

23. Baker TB, Piper ME, McCarthy DE, Majeskie MR, Fiore MC. Addiction motivation reformulated: an affective processing model of negative reinforcement. Psychol Rev 2004 Jan;111(1):33-51. [doi: 10.1037/0033-295X.111.1.33] [Medline: 14756584]

24. Ferguson SG, Shiffman S. The relevance and treatment of cue-induced cravings in tobacco dependence. J Subst Abuse Treat 2009 Apr;36(3):235-243. [doi: 10.1016/j.jsat.2008.06.005] [Medline: 18715743]

25. Conklin CA, Vella EJ, Joyce CJ, Salkeld RP, Perkins KA, Parzynski CS. Examining the relationship between cue-induced craving and actual smoking. Exp Clin Psychopharmacol 2015 Apr;23(2):90-96 [FREE Full text] [doi: 10.1037/a0038826] [Medline: 25730416 ]

26. Stevenson JG, Oliver JA, Hallyburton MB, Sweitzer MM, Conklin CA, McClernon FJ. Smoking environment cues reduce ability to resist smoking as measured by a delay to smoking task. Addict Behav 2017 Apr;67:49-52 [FREE Full text] [doi: 10.1016/j.addbeh.2016.12.007] [Medline: 28012965]

27. Bowen S, Chawla N, Collins SE, Witkiewitz K, Hsu S, Grow J, et al. Mindfulness-based relapse prevention for substance use disorders: a pilot efficacy trial. Subst Abus 2009;30(4):295-305 [FREE Full text] [doi: 10.1080/08897070903250084] [Medline: 19904665]

28. Brewer JA, Elwafi HM, Davis JH. Craving to quit: psychological models and neurobiological mechanisms of mindfulness training as treatment for addictions. Psychol Addict Behav 2013 Jun;27(2):366-379 [FREE Full text] [doi: 10.1037/a0028490] [Medline: 22642859]

29. Conklin C, Tiffany S. Applying extinction research and theory to cue-exposure addiction treatments. Addiction 2002 Mar;97(2):155-167. [doi: 10.1046/j.1360-0443.2002.00014.x] [Medline: 11860387]

30. Culbertson CS, Shulenberger S, De La Garza R, Newton TF, Brody AL. Virtual Reality Cue Exposure Therapy For The Treatment Of Tobacco Dependence. J Cyber Ther Rehabil 2012;5(1):57-64 [FREE Full text] [Medline: 25342999]

31. Hone-Blanchet A, Wensing T, Fecteau S. The use of virtual reality in craving assessment and cue-exposure therapy in substance use disorders. Front Hum Neurosci 2014;8:844 [FREE Full text] [doi: 10.3389/fnhum.2014.00844] [Medline: 25368571]

32. Powers MB, Emmelkamp PM. Virtual reality exposure therapy for anxiety disorders: A meta-analysis. J Anxiety Disord 2008;22(3):561-569. [doi: 10.1016/j.janxdis.2007.04.006] [Medline: 17544252]

33. Malbos E, Rapee RM, Kavakli M. A controlled study of agoraphobia and the independent effect of virtual reality exposure therapy. Aust N Z J Psychiatry 2013 Feb;47(2):160-168. [doi: 10.1177/0004867412453626] [Medline: 22790176]

34. Choi J, Park S, Lee J, Jung H, Lee H, Jin C, et al. The effect of repeated virtual nicotine cue exposure therapy on the psychophysiological responses: a preliminary study. Psychiatry Investig 2011 Jun;8(2):155-160 [FREE Full text] [doi: 10.4306/pi.2011.8.2.155] [Medline: 21852993] 
35. Moon J, Lee J. Cue exposure treatment in a virtual environment to reduce nicotine craving: a functional MRI study. Cyberpsychol Behav 2009 Feb;12(1):43-45. [doi: 10.1089/cpb.2008.0032] [Medline: 19025463]

36. Pericot-Valverde I, García-Rodríguez O, Ferrer-García M, Secades-Villa R, Gutiérrez-Maldonado J. Virtual reality for smoking cessation: a case report. Stud Health Technol Inform 2012;181:292-296. [Medline: 22954874]

37. Pericot-Valverde I, Secades-Villa R, Gutiérrez-Maldonado J. A randomized clinical trial of cue exposure treatment through virtual reality for smoking cessation. J Subst Abuse Treat 2019 Jan;96:26-32. [doi: 10.1016/j.jsat.2018.10.003] [Medline: 30466545]

38. Westbrook C, Creswell JD, Tabibnia G, Julson E, Kober H, Tindle HA. Mindful attention reduces neural and self-reported cue-induced craving in smokers. Soc Cogn Affect Neurosci 2013 Jan;8(1):73-84 [FREE Full text] [doi: 10.1093/scan/nsr076] [Medline: 22114078]

39. Garrison KA, Pal P, Rojiani R, Dallery J, O'Malley SS, Brewer JA. A randomized controlled trial of smartphone-based mindfulness training for smoking cessation: a study protocol. BMC Psychiatry 2015 Apr 14;15:83 [FREE Full text] [doi: 10.1186/s12888-015-0468-z] [Medline: 25884648]

40. Bowen S, Marlatt A. Surfing the urge: brief mindfulness-based intervention for college student smokers. Psychol Addict Behav 2009 Dec;23(4):666-671. [doi: 10.1037/a0017127] [Medline: 20025372]

41. Brewer JA, Mallik S, Babuscio TA, Nich C, Johnson HE, Deleone CM, et al. Mindfulness training for smoking cessation: results from a randomized controlled trial. Drug Alcohol Depend 2011 Dec 01;119(1-2):72-80 [FREE Full text] [doi: 10.1016/j.drugalcdep.2011.05.027] [Medline: 21723049]

42. Birckhead B, Khalil C, Liu X, Conovitz S, Rizzo A, Danovitch I, et al. Recommendations for Methodology of Virtual Reality Clinical Trials in Health Care by an International Working Group: Iterative Study. JMIR Ment Health 2019 Jan 31;6(1):e11973 [FREE Full text] [doi: 10.2196/11973] [Medline: 30702436]

43. Cobertura Universal de Salud. Como le ayudara este manual a dejar de fumar? Ministerio de Salud Argentina. Argentina: Ministerio de Salud; 2016. URL: http://www.msal.gob.ar/images/stories/ryc/graficos/ 0000000584cnt-2017-05 manual-autoayuda-dejar-de-fumar.pdf [accessed 2017-05-01]

44. Secretaría de Políticas Integrales sobre Drogas de la Nación Argentina (Sedronar). Tabaco-Alcohol: Intensidad del consumo. Estudio Nacional en población de 12 a 65 años sobre consumo de sustancias psicoactivas. Sedronar: Secretaria de Políticas Integrales sobre Drogas de la Nación Argentina. Argentina: Observatorio Argentino de Drogas; 2017. URL: http://www. observatorio.gov.ar/media/k2/attachments/InformeZconsumoZdeZTabaco_1.pdf [accessed 2017-05-01]

45. Biener L, Abrams DB. The Contemplation Ladder: validation of a measure of readiness to consider smoking cessation. Health Psychol 1991;10(5):360-365. [doi: 10.1037//0278-6133.10.5.360] [Medline: 1935872]

46. Bricker JB, Mull KE, Kientz JA, Vilardaga R, Mercer LD, Akioka KJ, et al. Randomized, controlled pilot trial of a smartphone app for smoking cessation using acceptance and commitment therapy. Drug Alcohol Depend 2014 Oct 01;143:87-94 [FREE Full text] [doi: 10.1016/j.drugalcdep.2014.07.006] [Medline: $\underline{25085225]}$

47. TypeForm.: Typeform URL: http://www.typeform.com [accessed 2017-11-01]

48. Kabat-Zinn J. An outpatient program in behavioral medicine for chronic pain patients based on the practice of mindfulness meditation: theoretical considerations and preliminary results. Gen Hosp Psychiatry 1982 Apr;4(1):33-47. [doi: 10.1016/0163-8343(82)90026-3] [Medline: 7042457]

49. Brewer J, Kabat-Zinn J. The Craving Mind: From Cigarettes to Smartphones to Love--Why We Get Hooked and How We Can Break Bad Habits. New Haven, CT: Yale Univerity Press; 2017:1-256.

50. Ferrer-García M, García-Rodríguez O, Gutiérrez-Maldonado J, Pericot-Valverde I, Secades-Villa R. Efficacy of virtual reality in triggering the craving to smoke: its relation to level of presence and nicotine dependence. Stud Health Technol Inform 2010;154:123-127. [Medline: 20543283]

51. Insta360.: Insta360 URL: http://www.insta360.com [accessed 2017-06-15]

52. Miralles I, Castilla D, Botella C. Desarrollo de un Entorno Virtual para la Inducción Emocional. In: I Congreso de la Sociedad Española para las Ciencias del Videojuego. 2014 Presented at: CEUR Workshop Proc; June 24, 2014; Barcelona, Spain.

53. Lee J, Lim Y, Graham SJ, Kim G, Wiederhold BK, Wiederhold MD, et al. Nicotine craving and cue exposure therapy by using virtual environments. Cyberpsychol Behav 2004 Dec;7(6):705-713. [doi: 10.1089/cpb.2004.7.705] [Medline: 15687806]

54. Amplitude.: Amplitude URL: http://www.amplitude.com [accessed 2017-11-15]

55. Zeng EY, Heffner JL, Copeland WK, Mull KE, Bricker JB. Get with the program: Adherence to a smartphone app for smoking cessation. Addict Behav 2016 Dec;63:120-124 [FREE Full text] [doi: 10.1016/j.addbeh.2016.07.007] [Medline: 27454354]

56. Cox LS, Tiffany ST, Christen AG. Evaluation of the brief questionnaire of smoking urges (QSU-brief) in laboratory and clinical settings. Nicotine Tob Res 2001 Feb;3(1):7-16. [doi: 10.1080/14622200020032051] [Medline: 11260806]

57. Anchorena M, Ghiglione F, Nader M. Psychometric Properties of the Five Facet Mindfulness Questionnaire in an Argentine Sample. Archives of Assessment Psychology 2017 Feb 23;7(1):29-41 [FREE Full text]

58. Heatherton T, Kozlowski L, Frecker R, Fagerström KO. The Fagerström Test for Nicotine Dependence: a revision of the Fagerström Tolerance Questionnaire. Br J Addict 1991 Sep;86(9):1119-1127. [doi: 10.1111/j.1360-0443.1991.tb01879.x] [Medline: 1932883] 
59. Iacoviello BM, Steinerman JR, Klein DB, Silver TL, Berger AG, Luo SX, et al. Clickotine, A Personalized Smartphone App for Smoking Cessation: Initial Evaluation. JMIR Mhealth Uhealth 2017 Apr 25;5(4):e56 [FREE Full text] [doi: 10.2196/mhealth.7226] [Medline: 28442453]

60. Bricker JB, Copeland W, Mull KE, Zeng EY, Watson NL, Akioka KJ, et al. Single-arm trial of the second version of an acceptance \& commitment therapy smartphone application for smoking cessation. Drug Alcohol Depend 2017 Jan 01;170:37-42 [FREE Full text] [doi: 10.1016/j.drugalcdep.2016.10.029] [Medline: 27870987]

61. Abroms LC, Boal AL, Simmens SJ, Mendel JA, Windsor RA. A randomized trial of Text2Quit: a text messaging program for smoking cessation. Am J Prev Med 2014 Sep;47(3):242-250 [FREE Full text] [doi: 10.1016/j.amepre.2014.04.010] [Medline: 24913220 ]

62. Thrul J, Klein AB, Ramo DE. Smoking Cessation Intervention on Facebook: Which Content Generates the Best Engagement? J Med Internet Res 2015 Nov 11;17(11):e244 [FREE Full text] [doi: 10.2196/jmir.4575] [Medline: 26561529]

63. Freeman D, Haselton P, Freeman J, Spanlang B, Kishore S, Albery E, et al. Automated psychological therapy using immersive virtual reality for treatment of fear of heights: a single-blind, parallel-group, randomised controlled trial. Lancet Psychiatry 2018 Aug;5(8):625-632 [FREE Full text] [doi: 10.1016/S2215-0366(18)30226-8] [Medline: 30007519]

64. Ahmed S, Sharmin M. Why do mobile phone-based smoking cessation interventions struggle and how can we make them more effective? iConference 2015 Proceedings 2015 Mar 15:2015 [FREE Full text]

65. Hughes J, Keely J, Naud S. Shape of the relapse curve and long-term abstinence among untreated smokers. Addiction 2004 Jan;99(1):29-38. [doi: 10.1111/j.1360-0443.2004.00540.x] [Medline: 14678060]

\author{
Abbreviations \\ ANOVA: analysis of variance \\ CBT: cognitive behavioral therapy \\ CG: control group \\ FFMQ: Five Facet Mindfulness Questionnaire \\ mHealth: mobile health \\ QSU: Questionnaire for Smoking Urges \\ TG: treatment group \\ VR: virtual reality \\ VR-CET: virtual reality cue exposure therapy \\ VRET: virtual reality exposure therapy \\ VR-MET: virtual reality mindful exposure therapy
}

Edited by G Eysenbach; submitted 21.12.19; peer-reviewed by A Miloff, O Perski; comments to author 19.03.20; revised version
received 08.04.20; accepted 03.06.20; published 29.07.20
Please cite as:
Goldenhersch E, Thrul J, Ungaretti J, Rosencovich N, Waitman C, Ceberio MR
Virtual Reality Smartphone-Based Intervention for Smoking Cessation: Pilot Randomized Controlled Trial on Initial Clinical Efficacy
and Adherence
J Med Internet Res 2020;22(7):e17571
URL: $\underline{\text { http://www.jmir.org/2020/7/e17571/ }}$
doi: $10.2196 / 17571$
PMID: $\underline{32723722}$

(CEmilio Goldenhersch, Johannes Thrul, Joaquín Ungaretti, Nicolas Rosencovich, Cristian Waitman, Marcelo Rodriguez Ceberio. Originally published in the Journal of Medical Internet Research (http://www.jmir.org), 29.07.2020. This is an open-access article distributed under the terms of the Creative Commons Attribution License (https://creativecommons.org/licenses/by/4.0/), which permits unrestricted use, distribution, and reproduction in any medium, provided the original work, first published in the Journal of Medical Internet Research, is properly cited. The complete bibliographic information, a link to the original publication on http://www.jmir.org/, as well as this copyright and license information must be included. 